\title{
Study of ill effects of air pollution due to automobiles on respiratory functions in traffic policemen
}

\author{
Dudhmal V ${ }^{1}$, Nawal SK ${ }^{2}$ \\ ${ }^{1}$ Dr. Vandana Dudhmal, Associate Professor Department of Physiology, K D Medical College, Mathura, ${ }^{2}$ Dr. Subodh \\ Kumar Nawal, Associate Professor, Pulmonary Medicine, SGT Medical College \& Hospital, Budera, Gurgaon, India
}

Address for correspondence: Dr Vandana Dudhmal, Email: vandana_kandhare@rediffmail.com

\begin{abstract}
Introduction: Every city is growing day by day and this growth is associated with enormous increase in vehicular traffic, emitting exhausts and polluting the atmosphere. vehicular population has been found to be an important cause of respiratory symptoms in city people.The adverse health effects and deterioration of pulmonary function from inhaling such particulate matters are well recognized. Although acute health effects have studied previously but chronic health effects related to outdoor traffic(automobiles) air population have not been evaluated that much. Material and Methods: A case control study was conducted in nanded city maharastra, A total of 120 subjects were studied in which 60 cases were smoker \& nonsmoker traffic policemen and 60 controls were nonsmoker\& not exposed to air pollution. Questionarre method used and respiratory functions (FVC, FEV1/FVC\%) were recorded by using spirometer. The statistical analysis was done by using SPSS software and unpaired t test was applied for results. Results: The respiratory functions including forced vital capacity(FVC), forced expiratory volume in one second and forced vital capacity ratio as percentage (FEV1/FVC\%) were reduced significantly in the traffic policemen than control group. Conclusion: Our study revealed that FVC had been significantly reduced in the traffic policemen suggesting restrictive pattern of lung disease.FEV1 and FEV1/FVC\% were also significantly reduced in traffic police men suggesting obstructive lung disease, Thus our findings are suggestive of mixed type of lung disease in them. So from this study it can be concluded that the traffic policemen are in very high risk group for respiratory dysfunction and further measures to reduce automobile pollution has to be required or studies to prevent them from automobile pollution exposure should be done in urgent basis.
\end{abstract}

Key words: Air Pollution, Respiratory Functions test, Forced vital capacity

\section{Introduction}

Indian cities are growing rapidly. This has led to an increase in the ownership and use of motor vehicles with a subsequent rise in the levels of air pollution.Especiallytraffic policemen are at high risk Automobile exhaust consists of oxides of nitrogen, carbon monoxide, particulate matter, and others, whichcause injury to the terminal bronchioles and decrease the pulmonary compliance and vital capacity $[1,2]$ The ultrafine particles of air pollutant can effect respiratory as well as cardiovascularsystems since ultrafine particle can easily enter in blood vessels[3,4,5,6]. The particles emitted from the vehicular exhaust of more than10-micron size are held in upper respiratory tract and particlesless than 10-

Manuscript received: $4^{\text {th }}$ June 2015

Reviewed: $14^{\text {th }}$ June 2015

Author Corrected: $24^{\text {th }}$ June 2015

Accepted for Publication: $3^{\text {rd }}$ July 2015 micron size (PM10) accumulates in the lung andproduces respiratory abnormalities. Hence, PM10 are of greatconcern in air pollution studies.Long-term exposure to traffic and PM2.5, at relatively low levels, was associated with lower FEV1 and FVC and an accelerated rate of lung function decline[7].

Investigations of the respiratory health effects fromvehicular pollution are necessary in order to predict the $[8,9,10]$ risk factors that may cause an asthmatic response. Since exposure to automobile pollution is a cause fordevelopment of acute or chronic respiratory disease, thepotential health risks in traffic policemen can be minimized by providing them with the information abouthazards of automobile pollution and about the protectivemeasures like provision of mask/protective device atindividual level or change of work atmosphere whenfeasible at higher level. Periodic 
retesting can detectpulmonary disease in the earliest stages when corrective measures are more likely to be beneficial.

\section{Material \& Methods}

The present study was designed to compare the respiratory function in a healthy working pollution who were working roadside (traffic policemen). Sixty city traffic policemen(smoker \& non smoker) and sixty contols(all male and non smoker) were investigated. All the subjects were male and mean age was found to be $37.88+$ 5.7. and all the controls had been age , height and weight matched.

Inclusion criteria for cases- traffic policemen(smoker \& nonsmoker)

Males

- No acute or chronic cardiopulmonary disease,

- No spine and chest deformties.

Inclusion criteria for controls- All healthy males, Non smokers

- No acute or chronic cardiopulmonary disease,

- No spine and chest deformties.

- Age, height and weight matched

Exclusion criteria:-

- Any evidence of chronic obstructive pulmonary disease, asthma, musculoskeletal abnormality, heart disease, anaemia, obesity and history of smoking.

- Any history of angina or chest pain, diabetes or hypertension.

- Non cooperation or inability to perform pulmonary function test.

Informed consent was taken from all subjects. The questionnaire used for this study was based on the American thoracic society questionnaire and division \& lung disease (ATS-DLD), which was developed by

\section{Results}

A total of 120 healthy males who met the inclusion criteria were studied. There were 60 subjects in each of the two groups i.e exposed to air pollution (traffic policemen) and not exposed to air pollution (control). The characteristics of the subjects are shown in Table No.1

Table No 1: Characteristics of subjects in the two groups.

\begin{tabular}{|l|l|l|}
\hline Variables & $\begin{array}{l}\text { Traffic Policemen group } \\
\mathbf{n = 6 0}\end{array}$ & $\begin{array}{l}\text { Control group } \\
\mathbf{N}=\mathbf{6 0}\end{array}$ \\
\hline Age $($ years $)$ & $37.88 \pm 7.52$ & $39.00 \pm 7.86$ \\
\hline Height $(\mathrm{cm})$ & $169.76 \pm 3.56$ & $170.12 \pm 6.42$ \\
\hline Weight $(\mathrm{kg})$ & $71.81 \pm 5.68$ & $70.92 \pm 6.42$ \\
\hline
\end{tabular}

Epidemiologist standardization project committee [11]. Respiratory functions had been recorded in sitting position using computerized "Medspiror"( RMS recorders and Medicare system, chandigarh, India) spirometer. The respiratory functions studied were forced vital capacity(FVC), Forced expiratory volume in first second(FEV1) and FEV1/FVC ratio. Before each test the subjects were familiarized with testing procedure. During the test, the subjects were adequately encouraged to perform at their optimum level and also a nose clip was applied during maneuver.All reading had been recorded at BTPS. Test had been repeated three times and the highest value was considered for statistical analysis. Subjects had been divided into two groups.

Group - I Case (traffic policemen $\mathrm{n}=60$ )

Group - II Control(who were not exposed to air pollution $\mathrm{n}=60$ )

Further to evaluate the effect of smoking in traffic policemen, they had been divided into two groups as-

I. Smoker traffic policemen $(n=18)$

II. Non smoker traffic policemen $(n=42)$

Type of Study- Case control study

\section{Statistical Analysis}

Statistical analysis was done by calculation of range, median, mean, standard deviation, percentage, student $t$ test and $\mathrm{p}$ value.

\section{Statistical software}

The statistical software SPSS 10.0 was used for the analysis of the data and Microsoft word and excel have been used to generate graphs, tables etc. 
Table No 2: Showing results of student $t$ test in two groups i.e traffic policemen and control

\begin{tabular}{|l|l|l|}
\hline Sr No. & Variable & 't' value \\
\hline 1. & FVC(Lit) $^{*}$ & 0.54 \\
\hline 2. & FEV1(Lit) $^{*}$ & 12.79 \\
\hline 3. & FEV1/FVC\% $^{*}$ & 3.29 \\
\hline
\end{tabular}

$* \mathrm{P}$ value- $<0.01$

Table No 3: showing results of student's t test in two groups i.e smoker traffic policemen and non smoker traffic policemen.

\begin{tabular}{|l|l|l|}
\hline Sr No. & Variable & 't' value \\
\hline 1. & FVC & 3.02 \\
\hline 2. & FEV1 & 2.48 \\
\hline 3. & FEV1/FVC & 3.38 \\
\hline
\end{tabular}

$* \mathrm{P}<0.05$

$* * \mathrm{P}<0.001$

Thus respiratory functions including forced vital capacity (FVC), forced expiratory volume in one second and forced vital capacity ratio as percentage (FEV1/FVC\%) were reduced significantly in the traffic policemen than control group. Also FVC, FEV1 and FEV1/FVC\% were reduced significantly in smoker group than non smoker group of traffic policemen.

\section{Discussion}

About 1.3 billion urban residents worldwide are exposed to air pollution level above recommended limits. Air quality in the developed countries has generally improved in the past two decades, but in many developing countries like India air quality has deteriorated because of rising industrial activity and congestion of streets with poorly maintained motor vehicles that use leaded fuel $[12,13]$.

Our study reveled that FVC had been significantly reduced in the traffic policemen suggesting restrictive pattern of lung disease. FEV1 and FEV1/FVC \% were also significantly reduced in traffic policemen suggesting obstructive lung disease. Thus our findings suggest mixed type of lung disease in traffic policemen. When we evaluated for effect of smoking, it has also shown significant reduction in FVC, FEV1 and FEV1/FVC\% in smoker traffic policemen as compared to non-smoker policemen suggesting that the smoker traffic policemen are more to develop respiratory dysfunction.

Sopan T.et al[1] study concludes that the traffic policemen are highly vulnerable for respiratory impairment due to vehicular exhaust at workplace environment. They observed FEV1 in traffic policemen was $2.27 \mathrm{~L}$, and in control group it was $2.81 \mathrm{~L}$. The FEV1 in traffic policemen was $73 \%$ of the expected value and in control group it was $118 \%$ of the expected value.

Pramila T.et al[14] found that The FEV /FVC ratio was also reduced in their study suggesting an obstructive type of respiratoryinvolvement. The pulmonary function parameters recorded using Kit micro RS 232 C, Computerised spirometer reflected an obstructive type of respiratory involvement in Traffic policemen.

There are various studies to found the role of dieasal particle in pulmonary function, Organic diesel exhaust particle chemicals also induce apoptosis and necrosis in bronchial epithelial cells via a mitochondrial pathway[15,16]. Diesel exhaust particles (DEP) are thought to consist of a carbon core surrounded by trace metals, such as nickel, and salts to which are adsorbed organic hydrocarbons. A number of these components have inflammatory effects in the lungs of laboratory animals. For example, intratracheal instillation of ultrafine carbon particles in rats leads to neutrophil influx into the lungs, and increase in bronchoalveolar lavage fluid (BALF) concentrations of tumour necrosis factor- (TNF) - alpha. Intratracheal instillation of nickel 
in rats causes severe and sustained inflammation, withgeneration of free radicals. Inhalation of hydrocarbons also leads to lung inflammation. Theforegoing observations indicate that diesel particles $[17,18]$ themselvescan induce airway inflammation . This may be the reason for decreased FVC and FEV and PEFR in traffic policemen.

Singhal MK et al[19] andLevsen K.et al[20] studied particles generated from diesel exhaust are extremelysmall and are present in the nuclei or accumulationmodes, with diameters of $0.02 \mathrm{~nm}$ and 0.2 nmrespectively. These small sized particles, by virtue of theirgreater surface area to mass ratio, can carry a much largerfraction of toxic compounds, such as hydrocarbons and metals on their surface. Hence chronic exposure to them can lead to chronic inflammation of respiratory tract and lung parenchyma .

R Sayyad et al[21] studied the effect of air pollution in non smoker traffic policemen and found that there is significant decrease in FVC $(\mathrm{P}<0.01)$, FEV1 $(\mathrm{P}<0.01)$, FEF-25-75\% $(\mathrm{P}<0.01)$, FEF75-85\% $(\mathrm{P}<0.02)$ and PEF $(<0.01)$ in study group compared to the control group. Significant changes of FVC and FEV1, may be due to small airway obstruction and which was confirmed by FEF25-75\% and PEF parameters results were similar our study.

Pravati Pal et al[22] also observed that FVC values (3.92 \pm 0.13 in Group-I and $3.56 \pm 0.11$ in Group- II) are significantly $(\mathrm{P}<0.05)$ reduces in the case group due to irritation in respiratory tract andweakness of respiratory muscles. FEV1/FVC indicates the condition of the bronchial musculature. In our study FEV1/FVC was statistically significant in traffic police men. It indicates that they are suffering from both obstructive and restrictive type of disorder in lungs. Wongsuraji et al [23] states that the traffic policemen had a significantly higher prevalence of abnormal air flow (FEV1 < 80\% predicted) than the control group $(21.1 \%$ vs. $12.4 \%, \mathrm{P}<$ 0.04). The mean values of FEV1 of the traffic policemenwere significantly lower than the control $\operatorname{group}(3.29 \pm 0.5 \mathrm{~L}$ vs. $3.43 \pm 0.5 \mathrm{~L}, \quad(\mathrm{P}<0.01)$. Thecondition of airways and flow of air through theairways are studied by the observation of FEF25$75 \%$, FEF75-85\% and PEF during theirperformance. Reduced FEF25-75\% in trafficpolice men shows smaller airway obstructionand reduced values of FEF75-85\% and PEFindicate that disturbance of air flow through the respiratory tracts. The other studies at Jaipur,India by Singh et al [24] also shows that highlysignificant $\quad(\mathrm{P} \quad<0.001)$ changes between controland subject groups in their investigation, similar to our study.

Thomas Go"tschi et al[25] study was to determine the association between long-term urban background air pollution and lung functionlevels, as well as change in lung function among European adults, Forced expiratory volume in $1 \mathrm{~s}$ (FEV1), forced vital capacity (FVC) and the ratio thereof (FEV1/FVC) were assessed at baseline andafter 9 years of follow-up in adults from 21 European centres(followed-up sample 5610). Fine particles (PM2.5) were measured in 2000/2001 using central monitors. They found despite sufficient statistical power no significant associations werefound between city-specific annual mean PM2.5 and average lung function levels. The findings also do not support an effect onchange in lung function, albeit statistical power was insufficient tosignificantly detect such an association.

\section{Conclusion}

The results of this study have shown a significant fall in pulmonary function parameters like FVC, PEFR, FEV /FVC in traffic policemen, Our study revealed that FVC had been significantly reduced in the traffic policemen suggesting restrictive pattern of lung disease.FEV1 and FEV1/FVC\% were also significantly reduced in traffic police men suggesting obstructive lung disease, Thus our findings are suggestive of mixed type of lung disease in them, and the parameters further reduced in smoker traffic policemen than non smokers.

\section{Conclusion}

Awareness must be created in the public regarding the harmful effect of traffic air pollution and advice should be given to switch off the engine in traffic queue. And government should make a provision of compulsory use of protective equipment (e.g. nose air filter masks) by traffic policemen working at heavy traffic junction.

\section{Funding: Nil \\ Conflict of interest: Nil \\ Permission from IRB: Yes}

\section{References}

1. Sopan T. Ingle, Bhushan G. Pachpande, Nilesh D. Wagh, Vijaybhai S. Patel and Sanjay B. Attarde. Exposure to vehicular pollution and 
respiratoryimpairment of traffic policemen in Jalgaon city, India. Ind Health. 2005 Oct;43(4):656-62.

2. Nicolai T, Carr D, Weiland SK, Duhma H, Ehrestein $\mathrm{OV}$, Wagner C, Mutlus EV. Urban traffic and pollutant exposure related to respiratory outcomes and atopy in a large sample of children. Eur Respir J. 2003 Jun;21(6):956-63.

3. Frampton MW. Systemic and cardiovascular effects of airway injury and inflammation: Ultrafine particle exposure in humans. Environ Health Perspect. 2001 Aug;109 Suppl 4:529-32.

4. Fung KY, Luginaah I, Gorey KM, Webster G. Air pollution and daily hospital admissions for cardiovascular diseases in Windsor, Ontario. Can J Public Health. 2005 Jan-Feb;96(1):29-33.

5. Pope CA III, Burnett RT, Thurston GD, Thun MJ, Calle EE, Krewski D, Godleski JJ. Cardiovascular mortality and long term exposure to particulate air pollution: epidemiological evidence of general pathophysiological pathways of disease. Circulation 2004; 109:71-77.

6. Routledge HC, Manney S, Harrison RM, Ayres JG,Townend JN. Effect of inhaled sulphur dioxide and carbon particles on heart rate variability and markers of inflammation and coagulation in human subjects. Heart. 2006 Feb;92(2):220-7. Epub 2005 May 27.

7. Rice MB, Ljungman PL, Wilker EH, Dorans KS, Gold DR, Schwartz J, Koutrakis P, Washko GR, O'Connor GT, Mittleman MA. Long-term exposure to traffic emissions and fine particulate matter and lung function decline in the Framingham heart study.Am $\mathbf{J}$ Respir Crit Care Med. 2015 Mar 15;191(6):656-64. doi: 10.1164/rccm.201410-1875OC.

8. Stone V. Environmental air pollution. Am J Respir Crit Care Med. 2000 Aug;162(2 Pt 2):S44-7.

9. Grahm NM. The epidemiology of acute respiratory infections in children and adults: a global prospective. Epidemiol Rev 1990; 12, 149-78.

10. Tiittnen P, Timonen KL, Ruuskanen J, Mirme A, Pekkanen J. Fine particulate air pollution, resuspended road dust and respiratory health among symptomatic children. Eur Respir J. 1999 Feb;13(2):266-73.
11. Georgewe, Melvyn ST, Knudje, etal. Standardized respiratory questionnares: comparison of the old with new. Am Rev Respir Dis. 1979 Jan;119(1):45-53.

12. World development report(1993), Investing in health Published for the world bank, oxford university press. Available on https://openknowledge.worldbank.org

13. Maxcy-Rosenau-Last Public Health and Preventive Medicine N Engl J Med 1993; 328:893-894.

14. Pramila T, B. Girija. Study of pulmonary function tests in traffic policemen exposed to automobile pollution in bangalore city. National Journal of Basic Medical Sciencesjan 2014; vol 4, issue 3.

15. Dickson RP, Schwartz DA. Acute and chronic responses to toxic inhalations. In: Fishman AP, Elias JA, Fishman JA, Grippi MA, Senior th RM, Pack AI, editors. Fishman's pulmonary diseases and disorders. 4 edition. China: Mc Graw Hill companies; 2008. p. 9951002.

16. Nel AE, Diaz-Sanchez D, Li N. The role of particulate pollutants in pulmonary inflammation and asthma: evidence for the involvement of organic chemicals and oxidative stress.curr opin pul med 2001 Jan; 7(1): 20-6.

17. Inoue KI, Takano H, Yanagisawa R, Ichinose $\mathrm{T}$, Shimada A, Yoshikawa T. Pulmonary exposure to diesel exhaust particles induces airway inflammation and cytokine expression in NC/Nga mice. Archives of Toxicology 2006; 79(10):595-599.

18. Nightingale JA, Maggs R, Cullinan P, Donnelly, Rogers DF, Kinnersley R, et al. Airway Inflammation after Controlled Exposure to Diesel Exhaust Particulate. Am. J. Respir. Crit. Care Med 2000; 162(1): 161- 166.

19. Singhal MK, Khaliq F, Singhal S, Tandon OP. Pulmonary functions in petrol pump workers: a preliminary study. Indian J Physiol Pharmacol 2007; 51(3):244-248.

20. Levsen K. The analysis of diesel particulate. Fresenius Z Anal Chem 1988; 331: 467-478.

21. R Sayyad, P K Yadav, M Sekhar, Aliyaraj A, evaluation of pulmonary function tests on non smoking 
traffic police men at tirupati, ap, india. Int $\mathrm{J}$ Physiother Res 2013, Vol1(5):279-82.

22. Pal P., John Robert A., Dutta T.K.. Pal G.K. pulmonary function tests in traffic police personal in Pondicherry. Indian $\mathbf{J}$ physiology and pharmacology 2010; 54(4): 329- 326.

23. Wongsurakiat $\mathrm{P}$, Maranetra KN, Nana A, Naruman C, Aksorint M, Chalermsanyakorn T, Respiratory symptoms and pulmonary function of traffic policemen in thorunburi. J, Med Asssocthai 1999; 82:435-443.
24. Singh V, Sharma BB, Yadav R, Meena P. Respiretory morbidity attributed to auto exhaust pollution in traffic policemen of jaipur, India. Asthma 2009; 46:118-21.

25. Thomas Go“tschi, Jordi Sunyer, Susan Chinn et al. Air pollution and lung function in the European Community Respiratory Health Survey. Int J Epidemiol. 2008 Dec; 37(6): 1349-1358.

\section{How to cite this article?}

Dudhmal V, Nawal SK. Study of ill effects of air pollution due to automobiles on respiratory functions in traffic policemen. Int J Med Res Rev 2015;3(6):623-628. doi: 10.17511/ijmrr.2015.i6.121. 